\section{Cartoon Editorial}

Check for updates

\title{
Students' and Teachers' Recognition of a Curriculum
}

\section{Beom Sun Chung (iD)}

Department of Anatomy, Ajou University School of Medicine, Suwon, Korea

- See the article "Evaluation of Medical Humanities Course in College of Medicine Using the Context, Input, Process, and Product Evaluation Model” in volume 34, number 22, e163.

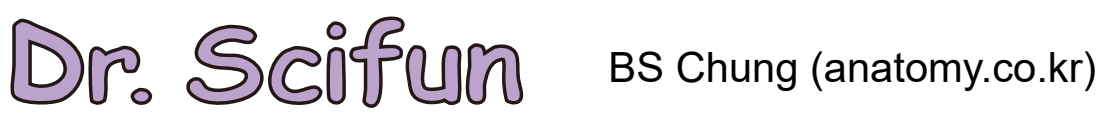

Accepted: Jun 5, 2019

Address for Correspondence:

Beom Sun Chung, MD

Department of Anatomy, Ajou University

School of Medicine, 164 World Cup-ro,

Yeongtong-gu, Suwon 16499 ,

Republic of Korea.

E-mail: bschung@ajou.ac.kr

(C) 2019 The Korean Academy of Medical

Sciences.

This is an Open Access article distributed under the terms of the Creative Commons Attribution Non-Commercial License (https:// creativecommons.org/licenses/by-nc/4.0/) which permits unrestricted non-commercial use, distribution, and reproduction in any

medium, provided the original work is properly cited.

ORCID iDs

Beom Sun Chung (iD)

https://orcid.org/0000-0002-3644-9120

Disclosure

The author has no potential conflicts of interest to disclose.
Students' and teachers' recognition of a curriculum

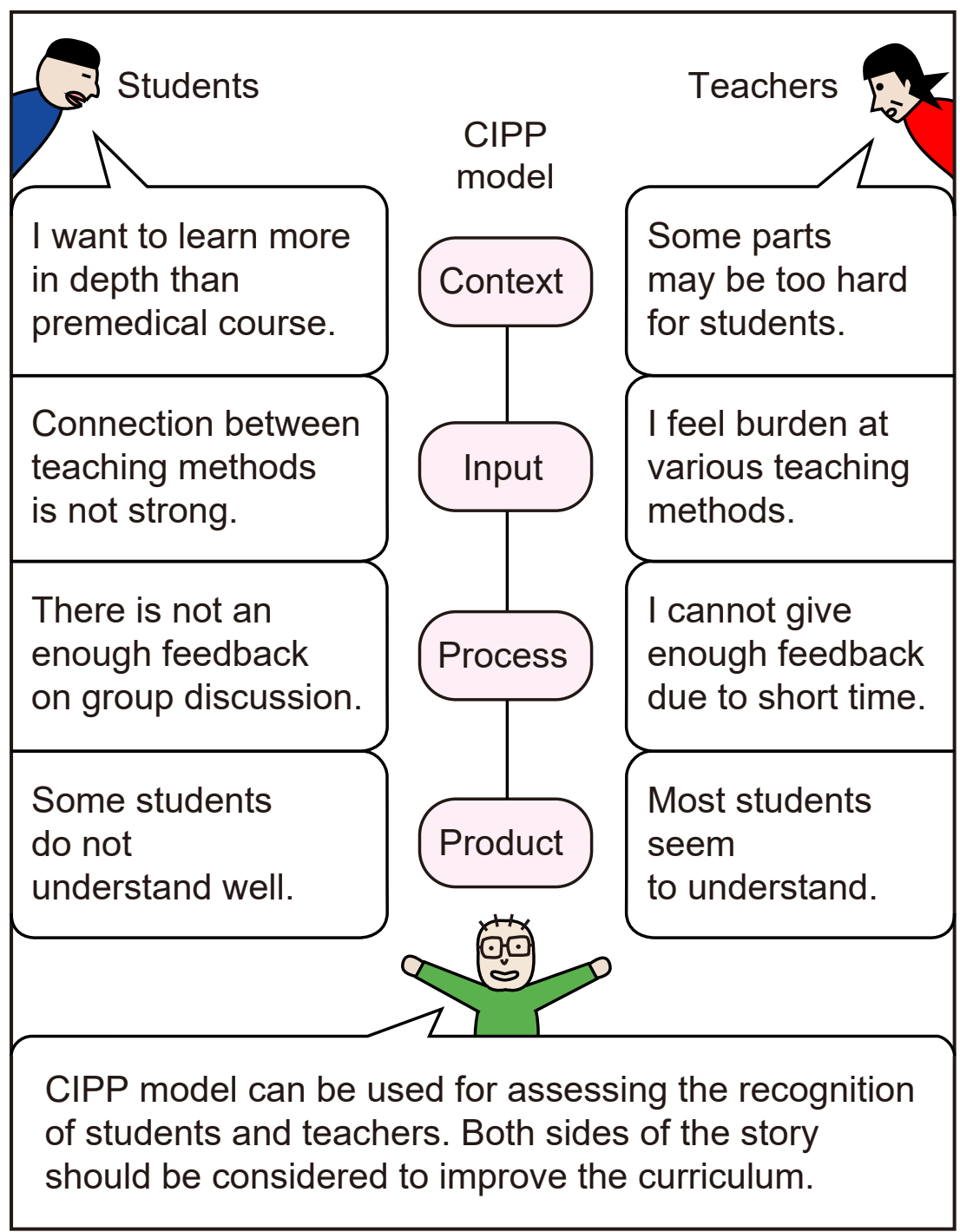

